\title{
BMJ Open Maternal urinary iodine concentration in pregnancy and children's cognition: results from a population-based birth cohort in an iodine-sufficient area
}

\author{
Akhgar Ghassabian, ${ }^{1,2}$ Jolien Steenweg-de Graaff, ${ }^{1,2}$ Robin P Peeters,, ${ }^{3,4}$ \\ H Alec Ross, ${ }^{5}$ Vincent W Jaddoe, ${ }^{2,6,7}$ Albert Hofman, ${ }^{7}$ Frank C Verhulst, ${ }^{1}$ \\ Tonya White, ${ }^{1,8}$ Henning Tiemeier ${ }^{1,7,9}$
}

To cite: Ghassabian A, Steenweg-de Graaff J, Peeters RP, et al. Maternal urinary iodine concentration in pregnancy and children's cognition: results from a population-based birth cohort in an iodine-sufficient area. BMJ Open 2014:4:e005520. doi:10.1136/bmjopen-2014005520

- Prepublication history for this paper is available online. To view these files please visit the journal online (http://dx.doi.org/10.1136/ bmjopen-2014-005520).

Received 21 April 2014 Revised 26 May 2014 Accepted 27 May 2014

CrossMark

For numbered affiliations see end of article.

Correspondence to Dr Akhgar Ghassabian; a.ghassabian@erasmusmc.nl

\section{ABSTRACT}

Objective: Reports from populations with an insufficient iodine intake suggest that children of mothers with mild iodine deficiency during pregnancy are at risk for cognitive impairments. However, it is unknown whether, even in iodinesufficient areas, low levels of iodine intake occur that influence cognitive development in the offspring. This study investigated the association between maternal low urinary iodine concentration (UIC) in pregnancy and children's cognition in a population-based sample from a country with an optimal iodine status (the Netherlands)

Setting and participants: In 1525 mother-child pairs in a Dutch multiethnic birth cohort, we investigated the relation between maternal UIC $<150 \mu \mathrm{g} / \mathrm{g}$ creatinine, assessed $<18$ weeks gestation and children's cognition.

Outcomes measures: Non-verbal IQ and language comprehension were assessed during a visit to the research centre using Dutch test batteries when the children were 6 years.

Results: In total, 188 (12.3\%) pregnant women had $\mathrm{UIC}<150 \mu \mathrm{g} / \mathrm{g}$ creatinine, with a median UIC equal to $119.3 \mu \mathrm{g} / \mathrm{g}$ creatinine. The median UIC in the group with UIC $>150 \mu \mathrm{g} / \mathrm{g}$ creatinine was $322.9 \mu \mathrm{g} / \mathrm{g}$ and in the whole sample $296.5 \mu \mathrm{g} / \mathrm{g}$ creatinine. There was a univariate association between maternal low UIC and children's suboptimum non-verbal IQ (unadjusted $\mathrm{OR}=1.44,95 \% \mathrm{Cl} 1.02$ to 2.02 ). However, after adjustment for confounders, maternal low UIC was not associated with children's non-verbal IQ (adjusted $\mathrm{OR}=1.33,95 \% \mathrm{Cl} 0.92$ to 1.93 ). There was no relation between maternal UIC in early pregnancy and children's language comprehension at 6 years.

Conclusions: The lack of a clear association between maternal low UIC and children's cognition probably reflects that low levels of iodine were not frequent and severe enough to affect neurodevelopment. This may result from the Dutch iodine fortification policy, which allows iodised salt to be added to almost all processed food and emphasises the monitoring of iodine intake in the population.

\section{Strengths and limitations of this study}

- The present study is performed in 1525 motherchild pairs from a country with optimal iodine intake (the Netherlands).

- In total, 188 pregnant women $(12.3 \%)$ had urinary iodine concentration $(\mathrm{UIC})<150 \mu \mathrm{g} / \mathrm{g}$ creatinine in early pregnancy.

- In this prospective study, there was no clear relation between maternal relatively low UIC and children's non-verbal IQ or language comprehension at age 6 years.

- As mild iodine deficiency was not prevalent in our sample, it is possible that we did not have the power to detect a significant association between maternal low UIC and children's cognitive delay.

- The lack of a clear association with children's cognitive abilities most likely reflects the fortification policy in the Netherlands, which allows iodised salt to be added to almost all processed foods and emphasises the monitoring of iodine intake in the population.

\section{INTRODUCTION}

Iodine is an essential micronutrient required for thyroid hormone production. Severe iodine deficiency is one of the major preventable causes of mental retardation worldwide. ${ }^{1}$ Owing to the iodine fortification of salt in many countries, severe iodine deficiency is a rare condition. ${ }^{2}$ Nevertheless, mild-to-moderate iodine deficiency is still considered a major public health concern, even in some developed countries. ${ }^{2}$

Pregnant women are particularly susceptible to iodine deficiency because of the higher requirement during pregnancy. ${ }^{3}$ Guidelines recommend an almost twofold increase in dietary iodine intake during pregnancy to maintain optimal thyroid hormone 
production in the mother and the fetus. ${ }^{3}{ }^{4}$ Randomised trials of iodine supplementation in pregnant women from regions with severe iodine deficiency confirmed the effect of maternal severe iodine deficiency on children's cognitive development. ${ }^{5}$ Recently, an observational study by Bath $e t a t^{6}$ in UK $(\mathrm{n}=1040)$ showed that the children born to mothers with mild-to-moderate iodine deficiency were at risk of impairments in non-verbal IQ and reading skills. In this study, mild-to-moderate iodine deficiency was defined as having urinary iodine concentration (UIC) lower than $150 \mu \mathrm{g} / \mathrm{g}$ of creatinine on the basis of WHO criteria. ${ }^{3}$ Similarly, in 228 mother-child pairs in Australia, Hynes et $a l^{\vec{l}}$ found a relation between maternal mild iodine deficiency (UIC $<150 \mu \mathrm{g} / \mathrm{L}$ ) and standardised academic test score, for example, spelling errors, in children. UK and Australia are considered mild-to-moderate iodinedeficient countries by the International Council for Control of Iodine Deficiency Disorders (ICCIDD). ${ }^{2}$ However, it is unclear whether relatively low levels of iodine intake during pregnancy also occur in countries with optimal iodine status, which affects cognitive development in the offspring.

The goal of this study was to investigate the association between maternal low UIC in pregnancy and children's cognition in a population-based sample from a country with an optimal iodine status (the Netherlands). ${ }^{2}$ UIC is a good marker of dietary iodine intake, and can be assessed reliably in spot urine samples at the population level. ${ }^{8}$ Adjustment of UIC for creatinine levels decreases the intraindividual variability in iodine excretion, and provides a more accurate estimate of iodine status in individuals compared to crude values. ${ }^{8}$

\section{METHODS}

\section{Participants}

This study was embedded within the Generation $\mathrm{R}$ Study, a population-based birth cohort in Rotterdam, the Netherlands, which follows children from fetal life onwards. ${ }^{9}$ In total, 7145 pregnant women were recruited in early pregnancy (gestational age $<18$ weeks). All women had a delivery date between April 2002 and January 2006. During early pregnancy, 2375 pregnant women provided urine samples. UIC was assessed in 2251 pregnant women with a singleton live birth. In this group, data on child cognitive measures were available in 1525 children at age 6 years. There was no difference in maternal iodine levels between mother-child pairs included in the analyses and those excluded because of missing data on child cognitive measures. Likewise, demographic characteristics including maternal age and education, household income or child's characteristics, such as gestational age at birth or ethnic background, did not differ between these two groups.

\section{Measurements}

During the first prenatal visit (mean gestational age $=13.28$ (1.85), range 6.07-17.93 weeks), maternal urine samples were collected at random times during the day. Urinary iodine was measured by the ceri-arsenite reaction after digestion by means of ammonium persulfate. After brief centrifugation, sodium arsenite solution $(0.1 \mathrm{~mol} / \mathrm{L}$ in $1 \mathrm{~mol} / \mathrm{L}$ of sulfuric acid $)$ was added. Subsequently, ceri-ammonium sulfate was added, and colour was allowed to develop at $250^{\circ} \mathrm{C}$ over $60 \mathrm{~min}$. Optical density was assessed at $405 \mathrm{~nm}$. At a concentration of $1.7 \mu \mathrm{mol} / \mathrm{L}$ iodine, the within-assay coefficient of variation $(\mathrm{CV})$ was $5.1 \%$ and the between-assay $\mathrm{CV}$ was $14.3 \%$. To adjust for total urinary volume, we used the UIC adjusted for creatinine levels (UIC/creatinine). We defined low UIC as values $<150 \mu \mathrm{g} / \mathrm{g}$ creatinine. To assess the iodine status of a population, the median (not the mean) UIC is recommended, as UICs are influenced by recent iodine intake. For pregnant populations, the median urinary iodine levels of $<150 \mu \mathrm{g} / \mathrm{L}$ are considered as insufficient, $150-249 \mu \mathrm{g} / \mathrm{L}$ as adequate and $>500 \mu \mathrm{g} / \mathrm{L}$ as excessive. ${ }^{3}$

At the age of six (mean age $=6.0 \pm 0.3$ years), the children were invited to visit the Generation $\mathrm{R}$ research centre. During this visit, children's non-verbal IQ and language comprehension were assessed using validated Dutch test batteries: two subtests of the Snijders-Oomen Niet-verbale intelligentie Test-Revisie (SON-R 21/2-7) and the receptive subtest of the Taaltest voor Kinderen (TvK). ${ }^{10} 11$

The subtests of SON-R 21/2-7 were Mosaics (assesses spatial visualisation abilities), and Categories (assesses abstract reasoning abilities). Raw test scores were converted into non-verbal IQ scores using norms tailored to exact age. For the receptive subtest of the TvK, the children were given 26 test items, and for each item they had to choose the best picture that matched the given words. We added the total correct answers for each child and divided this sum by the total number of items answered, yielding a percentage correct score. The correlation between non-verbal IQ and language comprehension scores was $r=0.42(p<0.001)$.

Information on birth date, sex and birth weight was obtained from registries. Gestational age at birth was established using an ultrasound examination during pregnancy. Birth order, parental age and education, marital status, ethnicity, household income and history of smoking, as well as child's history of breast feeding, were assessed by questionnaires. Child's ethnic background was defined based on the country of birth of both parents. Maternal education was defined by the highest completed education. Maternal smoking was assessed at enrolment and in mid and late pregnancy. Maternal weight and length were measured at enrolment and were used to calculate body mass index (BMI). In early pregnancy, maternal folate concentrations were analysed in plasma samples by using an immunoelectrochemiluminesence assay on the Architect System (Abbott Diagnostics BV). We used the Brief Symptom Inventory, a validated self-report questionnaire, to measure maternal psychopathology during pregnancy. In early pregnancy, maternal thyroid 
parameters (thyroid stimulating hormone (TSH) and free thyroxine) were measured in the blood. ${ }^{12}$ Maternal non-verbal IQ was assessed during the child's visit to the research centre, using a computerised version of the Ravens Advanced Progressive Matrices Test, set I. ${ }^{13}$

\section{Statistical analyses}

Mother-child pairs with data on UIC and one or more cognitive measures were included in the analyses. The percentage of missing data for covariates was below $10 \%$ except for maternal psychopathology during pregnancy $(17 \%)$, household income (17\%), paternal education $(32 \%)$ and child's history of breast feeding (13\%). Missing values were imputed using multiple imputations. Thirty copies of the original data set were generated with missing values replaced by values randomly generated from the predictive distribution, on the basis of the correlation between the variables.

Maternal low UIC during early pregnancy was the determinant in all analyses. We used linear regression to examine the relation between maternal low UIC and children's non-verbal IQ and language comprehension scores. Language comprehension scores were log transformed to meet the assumption of normality. To facilitate the interpretation of findings, we also used logistic regression to explore whether maternal low UIC was related to the odds of having a non-verbal IQ or language comprehension score in the lowest quartile of the sample (non-verbal IQ $<93$ and language comprehension score $<0.77)$. Potential confounders were selected on the basis of background knowledge. ${ }^{6} 7$ The relation between maternal UIC and children's cognition was examined in three steps: model 1, univariate association; model 2, adjusted for the child's sex and age, and maternal age and education; model 3, additionally adjusted for a child's ethnic background, birth order, history of breast feeding at age 6 months, paternal age, maternal BMI, maternal history of smoking, maternal IQ, marital status, paternal education, maternal psychopathology in pregnancy, maternal folate concentration in early pregnancy, household income and time of urine sampling in pregnancy. We additionally adjusted the models for maternal thyroid parameters.

\section{RESULTS}

Our results showed that Generation $\mathrm{R}$ participants were iodine sufficient, with median UIC=229.6 $\mathrm{g} / \mathrm{L} \quad(90 \%$ range 55.2-732.6; iodine to creatinine ratio $296.5 \mu \mathrm{g} / \mathrm{g}$ creatinine (90\% range $112.8-710.2)$ ). In total, 188 pregnant women $(12.3 \%)$ had $\mathrm{UIC}<150 \mu \mathrm{g} / \mathrm{g}$ creatinine; only 4 pregnant women had UIC $<50 \mu \mathrm{g} / \mathrm{g}$ creatinine. Iodine status of the mother in pregnancy was associated with maternal age, BMI, education, psychopathology scores in pregnancy, marital status and plasma folate levels in pregnancy (table 1$)$.

Table 2 represents the association between maternal iodine status in pregnancy and children's cognition at age 6 years. After adjustment for possible confounders, we did not find a relation between maternal low UIC and children's non-verbal IQ or language comprehension. Additional adjustment of the models for maternal thyroid parameters did not change the results ( $B$ additionally adjusted for maternal $\mathrm{TSH}=-0.87,95 \%$ CI -3.32 to $1.45 ; B$ additionally adjusted for maternal free thyroxine $=-0.86,95 \% \mathrm{CI}-3.19$ to 1.47$)$.

\section{DISCUSSION}

Convincing evidence from randomised controlled trials in severe iodine-deficient countries has shown the effectiveness of iodine fortification policies or supplementation in pregnant women. However, the existing evidence on the effectiveness of intervention in mild-to-moderate iodinedeficient areas is very limited with regard to an improvement in neurocognitive outcomes in children. ${ }^{14}$ The present study, performed in an iodine-sufficient country, showed no clear relation between maternal low UIC in early pregnancy and children's non-verbal IQ or language comprehension at age 6 years. There are several possible explanations for this finding. First, this study was performed in the Netherlands, which has a population with an adequate dietary iodine intake. ${ }^{15}$ Also, the median UIC in Generation $\mathrm{R}$ participants was much higher than the values reported in pregnant women of other populations (median UIC in this study=296.5 $\mu \mathrm{g} / \mathrm{g}$ creatinine, median UIC in the British study $=110 \mu \mathrm{g} / \mathrm{g}$ creatinine) ${ }^{6}{ }^{7}$ Even the median UIC levels in the 'low' group of Generation R (median $=119.3 \mu \mathrm{g} / \mathrm{g}$ creatinine) was higher than the median UIC in the total sample of previous studies. These levels document that the Generation $\mathrm{R}$ multiethnic urban sample is iodine sufficient. Furthermore, many pregnant women in our sample may have been mostly iodine sufficient during the period of preconception or early postnatal phase, despite the fact that we observed a spot UIC lower than $150 \mu \mathrm{g} / \mathrm{g}$ creatinine in pregnancy. A single measurement of urinary iodine is a good reflection of iodine status of a population, but may not necessarily reflect the iodine status of the individual. A second possible explanation is that the effect of iodine deficiency on a child's neurodevelopment may, to some extent, be specific to verbal and reading abilities, and less apparent in non-verbal skills. In the Generation R Study, we previously showed that low maternal UIC was related to poor working memory in children, but not to planning/organisation. ${ }^{16}$ The absence of any relation between maternal low iodine and cognitive aspects of executive function, in particular planning/organisation, is in line with the findings of the present study. The mechanisms through which mild iodine insufficiency influences other aspects of child neurodevelopment, such as working memory, are not clear. Third, despite a larger sample size compared to the British or Australian studies, the present study had a smaller group of women with $\mathrm{UIC}<150 \mu \mathrm{g} / \mathrm{g}$ creatinine (188 women in the present study and 646 women in the British study). As mild iodine deficiency is less prevalent in 
Table 1 Baseline characteristics $(n=1525)$

\begin{tabular}{|c|c|c|c|}
\hline & \multicolumn{3}{|c|}{ UIC adjusted for creatinine levels } \\
\hline & $<150 \mu \mathrm{g} / \mathrm{g}$ & $>150 \mu \mathrm{g} / \mathrm{g}$ & p Value \\
\hline \multicolumn{4}{|l|}{ Maternal characteristics } \\
\hline Age at enrolment, years & $30.8(4.6)$ & $28.6(5.3)$ & $<0.001$ \\
\hline Body mass index at enrolment & $24.4(4.3)$ & $25.3(5.1)$ & 0.01 \\
\hline \multicolumn{4}{|l|}{ Education, \% } \\
\hline Primary & 18.2 & 27.5 & \multirow[t]{3}{*}{0.01} \\
\hline Secondary & 54.3 & 52.2 & \\
\hline Higher education & 27.5 & 20.3 & \\
\hline Psychopathology score in pregnancy & $0.14(0.00-1.02)$ & $0.21(0.02-1.31)$ & $<0.001$ \\
\hline \multicolumn{4}{|l|}{ Smoking, \% } \\
\hline Never & 78.6 & 73.1 & \multirow[t]{3}{*}{0.24} \\
\hline Stopped when pregnant & 8.5 & 10.8 & \\
\hline Continued in pregnancy & 12.9 & 16.1 & \\
\hline \multicolumn{4}{|l|}{ Household income } \\
\hline$<€ 1200$ & 6.7 & 11.5 & \multirow[t]{3}{*}{0.10} \\
\hline$>€ 1200$ and $<€ 2000$ & 14.3 & 13.4 & \\
\hline$>€ 2000$ & 79.0 & 75.1 & \\
\hline Marital status, married/with partner \% & 90.4 & 78.9 & $<0.001$ \\
\hline Folate concentration in early pregnancy, $\mathrm{nmol} / \mathrm{L}$ & $19.2(9.2)$ & $17.2(8.2)$ & 0.004 \\
\hline Free thyroxine in early pregnancy, pmol/L & $15.28(0.22)$ & $14.94(0.09)$ & 0.15 \\
\hline Thyroid stimulating hormone in early pregnancy, $\mathrm{mU} / \mathrm{L}$ & $1.44(0.08)$ & $1.56(0.04)$ & 0.20 \\
\hline Maternal IQ score & $97(79-113)$ & $97(80-113)$ & 0.14 \\
\hline UIC adjusted for creatinine & $322.9(168.6-732.2)$ & $119.3(65.5-147.1)$ & $<0.001$ \\
\hline Gestational age at urine sampling & $13.1(10.5-16.8)$ & $12.9(10.2-16.5)$ & 0.55 \\
\hline \multicolumn{4}{|l|}{ Paternal characteristics } \\
\hline Age at enrolment, years & $33.5(5.8)$ & $31.9(6.2)$ & $<0.001$ \\
\hline \multicolumn{4}{|l|}{ Education, \% } \\
\hline Primary & 16.6 & 19.8 & \multirow[t]{3}{*}{0.23} \\
\hline Secondary & 46.6 & 51.3 & \\
\hline High & 36.8 & 28.9 & \\
\hline \multicolumn{4}{|l|}{ Child characteristics } \\
\hline Age at visit, years & $5.9(0.2)$ & $5.9(0.2)$ & 1.00 \\
\hline Sex, boy \% & 48.8 & 49.5 & 0.87 \\
\hline First born \% & 59.1 & 62.0 & 0.44 \\
\hline \multicolumn{4}{|l|}{ Ethnic background \% } \\
\hline Dutch & 57.5 & 57.2 & \multirow[t]{3}{*}{0.67} \\
\hline Other Western & 8.7 & 7.0 & \\
\hline Non-Western & 33.8 & 35.8 & \\
\hline Birth weight & $3441(521)$ & 3419 (493) & 0.60 \\
\hline Gestational age at birth & $40.3(37.4-42.1)$ & $40.3(37.2-41.9)$ & 0.90 \\
\hline Breast feeding at 6 months, yes & 35.6 & 26.7 & 0.03 \\
\hline IQ scores at 6 years & $102(15)$ & $100(16)$ & 0.12 \\
\hline Language comprehension score at 6 years & $0.85(0.62-0.96)$ & $0.85(0.61-0.96)$ & 0.87 \\
\hline
\end{tabular}

our sample, it is possible that we did not have the power to detect a significant association between maternal low UIC and children's cognitive delay. However, the observed effect sizes for low UIC in the present study (eg, OR=1.33, 95\% CI 0.92 to 1.92 for suboptimum non-verbal IQ) were very similar to those of the British study (OR=1.35, 95\% CI 0.93 to 1.94 ) for the comparable measure but did not reach the significance level in either study.

The infrequent occurrence of maternal low UIC during pregnancy and the lack of a clear association with children's cognitive abilities most likely reflect the Dutch government's iodine fortification policy, which allows iodised salt to be added to almost all processed food and emphasises the monitoring of iodine intake in the population. In case of non-optimal intake at the population level, governmental measures are taken to boost the supply of iodine in the population. ${ }^{15}$ This suggests that iodine fortification programmes can prevent adverse neurodevelopmental outcomes in children. 
Table 2 Maternal UIC adjusted for creatinine levels and children's non-verbal IQ and language comprehension at age 6 years

\begin{tabular}{|c|c|c|c|c|}
\hline \multirow[b]{2}{*}{$\begin{array}{l}\text { Determinant: } \\
\text { UIC }<150 \mu \mathrm{g} / \mathrm{g}\end{array}$} & \multicolumn{2}{|l|}{ Non-verbal IQ $(n=1450)$} & \multicolumn{2}{|c|}{ Language comprehension $(n=1319)$} \\
\hline & $\begin{array}{l}\text { Score } \\
B(95 \% \mathrm{Cl}), \mathrm{p} \text { value }\end{array}$ & $\begin{array}{l}\text { uboptimum ( } n=351) \\
R(95 \% \mathrm{Cl}), p \text { value }\end{array}$ & $\begin{array}{l}\text { Score } \\
B(95 \% \mathrm{Cl}), \mathrm{p} \text { value }\end{array}$ & $\begin{array}{l}\text { Suboptimum } \\
(n=323) \\
\text { OR }(95 \% \text { Cl), p value }\end{array}$ \\
\hline & & & & \\
\hline & & & & \\
\hline odel 3 & $-0.86(-3.10$ to 1.38$), 0.45$ & $1.33(0.92$ to 1.92$), 0.13$ & $0.004(-0.02$ to 0.03$), 0.72$ & \\
\hline \multicolumn{5}{|c|}{$\begin{array}{l}\text { Suboptimum non-verbal IQ: score in the lowest quartile (IQ scores <93). } \\
\text { Language score was log-transformed to satisfy the assumption of normality. } \\
\text { Suboptimum language comprehension: scores in the lowest quartile (language comprehension scores <0.77). } \\
\text { Model 1: unadjusted. } \\
\text { Model 2: adjusted for child's sex and age at the time of cognitive assessment, maternal age and maternal educational levels. } \\
\text { Model 3: adjusted for child's sex and age at the time of cognitive assessment, ethnic background, birth order and history of breast feeding at } \\
\text { age } 6 \text { months, and parental age at the time of pregnancy, maternal body mass index, maternal history of smoking, maternal IQ, marital status, } \\
\text { parental educational levels, maternal psychopathology in pregnancy, maternal folate concentration in early pregnancy, household income and } \\
\text { time of urine sampling in pregnancy. } \\
\text { UIC, urinary iodine concentration. }\end{array}$} \\
\hline
\end{tabular}

\section{Author affiliations}

${ }^{1}$ Department of Child and Adolescent Psychiatry, Erasmus Medical Centre Sophia Children's Hospita, Rotterdam, The Netherlands

${ }^{2}$ The Generation R Study Group, Erasmus Medical Centre, Rotterdam,

The Netherlands

${ }^{3}$ Department of Internal Medicine, Erasmus Medical Centre, Rotterdam, The Netherlands

${ }^{4}$ Rotterdam Thyroid Centre, Erasmus Medical Centre, Rotterdam,

The Netherlands

${ }^{5}$ Department of Laboratory Medicine, Radboud University Nijmegen Medical Centre, Nijmegen, The Netherlands

${ }^{6}$ Department of Paediatrics, Erasmus Medical Centre - Sophia Children's Hospital, The Netherlands

${ }^{7}$ Department of Epidemiology, Erasmus Medical Centre, Rotterdam,

The Netherlands

${ }^{8}$ Department of Radiology, Erasmus Medical Centre, Rotterdam,

The Netherlands

${ }^{9}$ Department of Psychiatry, Erasmus Medical Centre, Rotterdam,

The Netherlands

Contributors VWJ, AH, FCV, TW and HT designed the manuscript; AG, HAR and $H T$ were involved in acquisition of the data; $A G$ and $H T$ participated in analysis of the data; AG, JS-dG, RPP, TW and HT participated in interpretation of the data; $A G$ and $H T$ participated in drafting of the article; AG; JS-dG, HAR, VWJ, AH, FCV, TW and HT participated in critical revision of the manuscript for important intellectual content.

Funding The Generation R Study is conducted by the Erasmus Medical Centre in close collaboration with the Municipal Health Service Rotterdam area, Rotterdam, the Rotterdam Homecare Foundation, Rotterdam and the Stichting Trombosedienst \& Artsenlaboratorium Rijnmond (STAR-MDC), Rotterdam. The work of HT and AG was supported by a research grant from the European Community's 7th Framework Programme (FP7/2008-2013) under grant agreement 212652 (NUTRIMENTHE project, 'The Effect of Diet on the Mental Performance of Children').

Competing interests None.

Ethics approval The Medical Ethics Committee of the Erasmus Medical Centre approved the study, and written informed consent was obtained from parents.

Provenance and peer review Not commissioned; externally peer reviewed.

Data sharing statement No additional data are available.

Open Access This is an Open Access article distributed in accordance with the Creative Commons Attribution Non Commercial (CC BY-NC 3.0) license, which permits others to distribute, remix, adapt, build upon this work non- commercially, and license their derivative works on different terms, provided the original work is properly cited and the use is non-commercial. See: http:// creativecommons.org/licenses/by-nc/3.0/

\section{REFERENCES}

1. Zimmermann MB, Jooste PL, Pandav CS. lodine-deficiency disorders. Lancet 2008;372:1251-62.

2. Pearce EN, Andersson M, Zimmermann MB. Global iodine nutrition: where do we stand in 2013? Thyroid 2013;23:523-8.

3. Stagnaro-Green A, Abalovich M, Alexander E, et al. Guidelines of the American Thyroid Association for the diagnosis and management of thyroid disease during pregnancy and postpartum. Thyroid 2011;21:1081-125.

4. De Groot L, Abalovich M, Alexander EK, et al. Management of thyroid dysfunction during pregnancy and postpartum: an Endocrine Society clinical practice guideline. J Clin Endocrinol Metab 2012;97:2543-65.

5. Zhou SJ, Anderson AJ, Gibson RA, et al. Effect of iodine supplementation in pregnancy on child development and other clinical outcomes: a systematic review of randomized controlled trials. Am J Clin Nutr 2013;98:1241-54.

6. Bath SC, Steer CD, Golding J, et al. Effect of inadequate iodine status in UK pregnant women on cognitive outcomes in their children: results from the Avon Longitudinal Study of Parents and Children (ALSPAC). Lancet 2013;382:331-7.

7. Hynes KL, Otahal P, Hay I, et al. Mild iodine deficiency during pregnancy is associated with reduced educational outcomes in the offspring: 9-year follow-up of the gestational iodine cohort. J Clin Endocrinol Metab 2013;98:1954-62.

8. Vejbjerg P, Knudsen N, Perrild H, et al. Estimation of iodine intake from various urinary iodine measurements in population studies. Thyroid 2009;19:1281-6.

9. Jaddoe VW, van Duijn CM, Franco $\mathrm{OH}$, et al. The Generation $\mathrm{R}$ Study: design and cohort update 2012. Eur J Epidemiol 2012;27:739-56.

10. Tellegen PJ, Winkel M, Wijnberg-Williams B, et al. Snijders-Oomen niet-verbale intelligentietest: SON-R 2 1/2-7. Amsterdam: Boom Testuitgevers, 2005

11. Van Bon WHJ. Taaltests voor kinderen. Lisse: Swets \& Zeitlinger, 1982.

12. Ghassabian A, Bongers-Schokking JJ, Henrichs J, et al. Maternal thyroid function during pregnancy and behavioral problems in the offspring: the Generation R Study. Pediatr Res 2011;69:454-9.

13. Prieler J. Raven's advanced progressive matrices. Vol 24. Mödling, Austria: Schufried, 2003.

14. Taylor PN, Okosieme OE, Dayan CM, et al. Therapy of endocrine disease: impact of iodine supplementation in mild-to-moderate iodine deficiency: systematic review and meta-analysis. Eur J Endocrinol 2014;170:R1-15.

15. National Institute for Public Health and the Environment. The iodine intake of children and adults in the Netherlands: results of the Dutch National Food Consumption Survey 2007-2010. 2012. http://www. 
rivm.nl/en/Documents and_publications/Scientific/Reports/2012/ april/The_iodine_intake_of_children_and_adults_in_the_

Netherlands_Results_of_the_Dutch_National_Food_Consumption

Survey 2007 2010 (accessed 5 Mar 2014).
16. van Mil $\mathrm{NH}$, Tiemeier $\mathrm{H}$, Bongers-Schokking JJ, et al. Low urinary iodine excretion during early pregnancy is associated with alterations in executive functioning in children. $J$ Nutr 2012;142:2167-74. 


\section{Correction}

Ghassabian A, Steenweg-de Graaff J, Peeters RP, et al. Maternal urinary iodine concentration in pregnancy and children's cognition: results from a population-based birth cohort in an iodine-sufficient area. BMJ Open 2014;4:e005520. doi:10.1136/ bmjopen-2014- 005520

The column headers in Table 1 are the wrong way round; ' $<150 \mu \mathrm{g} / \mathrm{g}$ ' should be '>150 $\mu \mathrm{g} / \mathrm{g}$ ' and vice versa. Please see the corrected Table 1 below:

\begin{tabular}{|c|c|c|c|}
\hline & \multicolumn{3}{|c|}{ UIC adjusted for creatinine levels } \\
\hline & $>150 \mu \mathrm{g} / \mathrm{g}$ & $<150 \mu \mathrm{g} / \mathrm{g}$ & p Value \\
\hline \multicolumn{4}{|l|}{ Maternal characteristics } \\
\hline Age at enrolment, years & $30.8(4.6)$ & $28.6(5.3)$ & $<0.001$ \\
\hline Body mass index at enrolment & $24.4(4.3)$ & $25.3(5.1)$ & 0.01 \\
\hline \multicolumn{4}{|l|}{ Education, \% } \\
\hline Primary & 18.2 & 27.5 & \multirow[t]{3}{*}{0.01} \\
\hline Secondary & 54.3 & 52.2 & \\
\hline Higher education & 27.5 & 20.3 & \\
\hline $\begin{array}{l}\text { Psychopathology score in } \\
\text { pregnancy }\end{array}$ & $0.14(0.00-1.02)$ & $0.21(0.02-1.31)$ & $<0.001$ \\
\hline \multicolumn{4}{|l|}{ Smoking, \% } \\
\hline Never & 78.6 & 73.1 & \multirow[t]{3}{*}{0.24} \\
\hline Stopped when pregnant & 8.5 & 10.8 & \\
\hline Continued in pregnancy & 12.9 & 16.1 & \\
\hline \multicolumn{4}{|l|}{ Household income } \\
\hline$<€ 1200$ & 6.7 & 11.5 & \multirow[t]{3}{*}{0.10} \\
\hline$>€ 1200$ and $<€ 2000$ & 14.3 & 13.4 & \\
\hline$>€ 2000$ & 79.0 & 75.1 & \\
\hline $\begin{array}{l}\text { Marital status, married/with } \\
\text { partner } \%\end{array}$ & 90.4 & 78.9 & $<0.001$ \\
\hline $\begin{array}{l}\text { Folate concentration in early } \\
\text { pregnancy, } \mathrm{nmol} / \mathrm{L}\end{array}$ & $19.2(9.2)$ & $17.2(8.2)$ & 0.004 \\
\hline $\begin{array}{l}\text { Free thyroxine in early pregnancy, } \\
\mathrm{pmol} / \mathrm{L}\end{array}$ & $15.28(0.22)$ & $14.94(0.09)$ & 0.15 \\
\hline $\begin{array}{l}\text { Thyroid stimulating hormone in } \\
\text { early pregnancy, } \mathrm{mU} / \mathrm{L}\end{array}$ & $1.44(0.08)$ & $1.56(0.04)$ & 0.20 \\
\hline Maternal IQ score & $97(79-113)$ & $97(80-113)$ & 0.14 \\
\hline UIC adjusted for creatinine & 322.9 (168.6-732.2) & $119.3(65.5-147.1)$ & $<0.001$ \\
\hline Gestational age at urine sampling & $13.1(10.5-16.8)$ & $12.9(10.2-16.5)$ & 0.55 \\
\hline \multicolumn{4}{|l|}{ Paternal characteristics } \\
\hline Age at enrolment, years & $33.5(5.8)$ & $31.9(6.2)$ & $<0.001$ \\
\hline \multicolumn{4}{|l|}{ Education, \% } \\
\hline Primary & 16.6 & 19.8 & \multirow[t]{3}{*}{0.23} \\
\hline Secondary & 46.6 & 51.3 & \\
\hline High & 36.8 & 28.9 & \\
\hline \multicolumn{4}{|l|}{ Child characteristics } \\
\hline Age at visit, years & $5.9(0.2)$ & $5.9(0.2)$ & 1.00 \\
\hline Sex, boy \% & 48.8 & 49.5 & 0.87 \\
\hline First born \% & 59.1 & 62.0 & 0.44 \\
\hline \multicolumn{4}{|l|}{ Ethnic background \% } \\
\hline Dutch & 57.5 & 57.2 & \multirow[t]{3}{*}{0.67} \\
\hline Other Western & 8.7 & 7.0 & \\
\hline Non-Western & 33.8 & 35.8 & \\
\hline Birth weight & 3441 (521) & 3419 (493) & 0.60 \\
\hline Gestational age at birth & $40.3(37.4-42.1)$ & $40.3(37.2-41.9)$ & 0.90 \\
\hline
\end{tabular}


Table 1 Continued

\begin{tabular}{lccc}
\hline & UIC adjusted for creatinine levels & \\
\cline { 2 - 4 } & $>\mathbf{1 5 0} \boldsymbol{\mu \mathbf { g } / \mathbf { g }}$ & $\mathbf{< 1 5 0} \boldsymbol{\mu g} \mathbf{g}$ & $\mathbf{p}$ Value \\
\hline Breast feeding at 6 months, yes & 35.6 & 26.7 & 0.03 \\
IQ scores at 6 years & $102(15)$ & $100(16)$ & 0.12 \\
Language comprehension score & $0.85(0.62-0.96)$ & $0.85(0.61-0.96)$ & 0.87 \\
at 6 years & & \\
\hline Numbers are mean (SD) for variables with normal distribution, median (90\% range) for not normally \\
distributed variables and percentages for categorical variables. \\
UIC, urinary iodine concentration.
\end{tabular}

Open Access This is an Open Access article distributed in accordance with the Creative Commons Attribution Non Commercial (CC BY-NC 4.0) license, which permits others to distribute, remix, adapt, build upon this work noncommercially, and license their derivative works on different terms, provided the original work is properly cited and the use is non-commercial. See: http://creativecommons.org/licenses/by-nc/4.0/

BMJ Open 2017;7:e005520corr1. doi:10.1136/bmjopen-2014-005520corr1

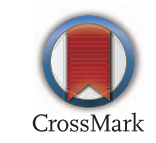




\section{Correction}

Dudley L, Kettle C, Thomas PW, et al. Perineal resuturing versus expectant management following vaginal delivery complicated by a dehisced wound (PREVIEW): a pilot and feasibility randomised controlled trial. BMJ Open 2017;7:e012766. doi:10.1136/bmjopen-2016-012766

The superscript " 3 " should not be next to author Lynn Dudley as this is not one of their affiliations.

Open Access This is an Open Access article distributed in accordance with the terms of the Creative Commons Attribution (CC BY 4.0) license, which permits others to distribute, remix, adapt and build upon this work, for commercial use, provided the original work is properly cited. See: http://creativecommons.org/licenses/by/4.0/

BMJ Open 2017;7:e012766corr1. doi:10.1136/bmjopen-2016-012766corr1

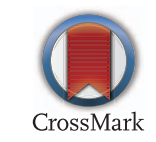

